\title{
Using Citizen-science Reports to Document Range Expansion of the Introduced Chinese Water Dragion (Physignathus cocincinus) in Hong Kong
}

Matthew Mo

P.O. Box A290, Sydney South, NSW 1232, Australia (matthew.sk.mo@gmail.com)

\begin{abstract}
The first incursion of Chinese Water Dragons (Physignathus cocincinus) in Hong Kong occurred in October 2004 on Tsing Yi Island. This study identified a further 54 citizen-science reports of dragons in different locations of Hong Kong. Although there were no subsequent reports from Tsing Yi Island, there were recurring reports in five other locations. In Aberdeen, reports started in 2010, concentrating on the grounds of Ocean Park. There were also numerous reports from the Kam Shan Country Park since 2010, the Pok Fu Lam Reservoir since 2011, the Lion Rock Country Park since 2012, and the Sha Tin District since 2014. Dragons were mostly observed in natural areas, but also in urban areas. The highest number of sightings were reported in April. Combinations of males and females were identified in four of the locations with numerous reports, suggesting that these populations are self-sustaining.
\end{abstract}

Ap range of exotic lizards, snakes, and turtles are traded as pets throughout the world (Stringham and Lockwood 2018). In Hong Kong, pet releases are believed to be the main cause of invasive species incursions. The Red-eared Slider (Trachemys scripta elegans) is the most commonly observed invasive reptile, often seen in urban ponds and waterways (Lau et al. 2000). Recently, possible specimens of other North American chelonians have also been recorded (Mo 2019). Brook's House Gecko (Hemidactylus brookii), found only in the Western District of Hong Kong Island and Ngau Chi Wan (Corlett 1992; Chan et al. 2006), also is believed to be introduced.

The Chinese Water Dragon (Physignathus cocincinus; Fig. 1) is an agamid lizard that occurs naturally in China, Thailand, Laos, and Vietnam. The species had not been recorded previously in inventories of herpetofauna in Hong Kong (e.g., Bogadek and Lau 1997; Karsen et al. 1998) but has long been traded locally as a pet (Lau et al. 1997; pers. obs.). The first known incursion of this species was on Tsing Yi Island in October 2004 (To 2005). This population comprised at least three mature males and two females, as well as three juveniles. Thus the potential to establish a growing population existed. Chinese Water Dragons have been reported subsequently from other locations in Hong Kong. The goal of this study was to use information gleaned from citizen-science reports to determine the current geographical extent of the Chinese Water Dragon in Hong Kong.
I collated reports of Chinese Water Dragons in Hong Kong from social media, citizen-scientists, photographysharing platforms, such as iNaturalist and Flickr, and from observers known to me. Photographs and descriptions were used to verify species identifications in these reports, as well as to determine whether the dragons were adult males, females,

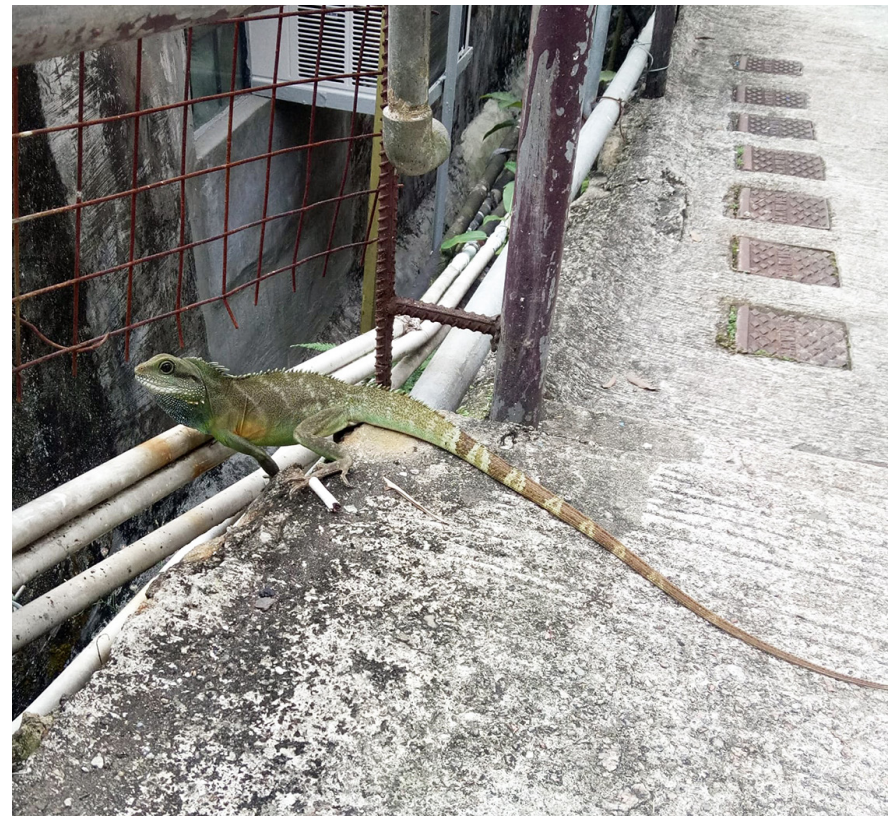

Fig. 1. An adult male Chinese Water Dragon (Physignathus cocincinus) in the Ha Wo Che Village, the Sha Tin District. Photograph by D. and T. Mo. 
or juveniles. Photographs and descriptions also were useful for determining the land use patterns where dragons were observed. After arranging the observations chronologically, I analyzed the resultant dataset to determine sex ratios in adult dragons and the proportion of juveniles. Further analysis of the dataset quantified seasonality and frequency of observations in areas subjected to different land uses.

\section{Chronology of reports of the Chinese Water Dragon.-} Since the initial incursion on Tsing Yi Island (To 2005), at least 54 additional reports have documented the presence of Chinese Water Dragons at different locations in Hong Kong (Table 1), but no further observations on Tsing Yi Island. Between 2010 and 2014, reports of dragons were focused in seven locations (Fig. 2), for five of which recurring reports indicated that populations were established:

Aberdeen.- The first report of a Chinese Water Dragon in Aberdeen was on the grounds of Ocean Park in July 2010. An extensive lull in further reports prevailed until numerous observations were reported in April 2018. Other reports from Aberdeen include one dragon found in a housing estate in April 2018 and two reports from the Aberdeen Reservoir in July and September 2018. Reports from Aberdeen account for $17 \%$ of all reports of the Chinese Water Dragon in Hong Kong.

Kam Shan Country Park.-One dragon was reported in the Kam Shan Country Park in September 2010. This observation was near the reservoir, which was close to another sighting in May 2010. One further report in this vicinity was a dragon found in Wonderland Villas, an urban area close to the country park, in October 2010.

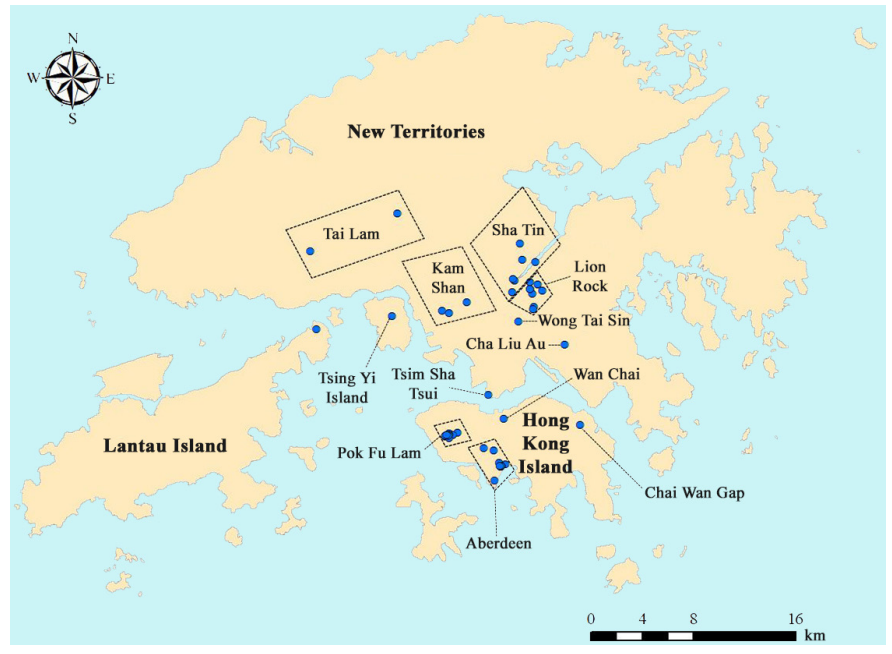

Fig. 2. Geographical distribution of reports of the Chinese Water Dragon (Physignathus cocincinus) in Hong Kong. Concentrations of reports are shown as groups.

Pok Fu Lam Reservoir.-Dragons were first reported at the Pok Fu Lam Reservoir in June and July 2011. A steady number of reports have continued from 2016 to the present.

Lion Rock Country Park.-The earliest report in the Lion Rock Country Park was a dragon seen in July 2012. At least six additional sightings of dragons have been reported since September 2016.

Sha Tin District.- Reports of dragons in urban areas of the Sha Tin District have been more recent, beginning in September 2014. In July 2016, one dragon was observed in a natural area in Fo Tan. Since then, reports have documented dragons in the Sha Tin District each year (Fig. 1).

Table 1. Time-scaled representation of reports of the Chinese Water Dragon (Physignathus cocincinus) in different regions of Hong Kong. ${ }^{1}$ Lantau Island in 2013, Tsim Sha Tsui in 2016, Wong Tai Sin in 2017, and Wan Chai and Chai Wan Gap in 2018. ${ }^{2}$ Information from To (2005).

\begin{tabular}{|c|c|c|c|c|c|c|c|c|}
\hline & Aberdeen & $\begin{array}{c}\text { Kam Shan } \\
\text { Country } \\
\text { Park }\end{array}$ & $\begin{array}{c}\text { Lion Rock } \\
\text { Country } \\
\text { Park }\end{array}$ & $\begin{array}{l}\text { Pok Fu Lam } \\
\text { Reservoir }\end{array}$ & $\begin{array}{l}\text { Sha Tin } \\
\text { District }\end{array}$ & $\begin{array}{c}\text { Tai Lam } \\
\text { Country } \\
\text { Park }\end{array}$ & $\begin{array}{l}\text { Tsing Yi } \\
\text { Island }\end{array}$ & $\begin{array}{l}\text { Isolated } \\
\text { reports }^{1}\end{array}$ \\
\hline $2004-5$ & & & & & & & $8^{2}$ & \\
\hline 2010 & 1 & 1 & & & & & & \\
\hline 2011 & & & & 2 & & & & \\
\hline 2012 & & & 1 & 3 & & 1 & & \\
\hline 2013 & & & & & & & & 1 \\
\hline 2014 & & & & & 1 & & & \\
\hline 2016 & & & 1 & 1 & 1 & & & 1 \\
\hline 2017 & & & & 1 & 1 & & & 1 \\
\hline 2018 & 14 & 2 & 4 & 4 & 2 & 1 & & 2 \\
\hline 2019 & & & 1 & 3 & 2 & & & \\
\hline Total & 15 & 3 & 7 & 14 & 7 & 2 & 8 & 5 \\
\hline
\end{tabular}


Established populations also are known from the Kowloon and Shing Mun reservoirs (P. Crow, pers. comm.) but were not represented in the dataset. However, at least two reports were from the Tai Lam Country Park. One dragon was sighted near the reservoir in August 2012 and a second dragon was located in the forest in August 2018. Isolated sightings of dragons also were made on Lantau Island in September 2013, Tsim Sha Tsui in June 2016, Wong Tai Sin in August 2017, Wan Chai in April 2018, and Chai Wan Gap in November 2018.

Patterns in reports of Chinese Water Dragons.-In most reports, dragons were observed in natural areas, particularly near reservoirs (Fig. 3). In contrast, urban areas accounted for

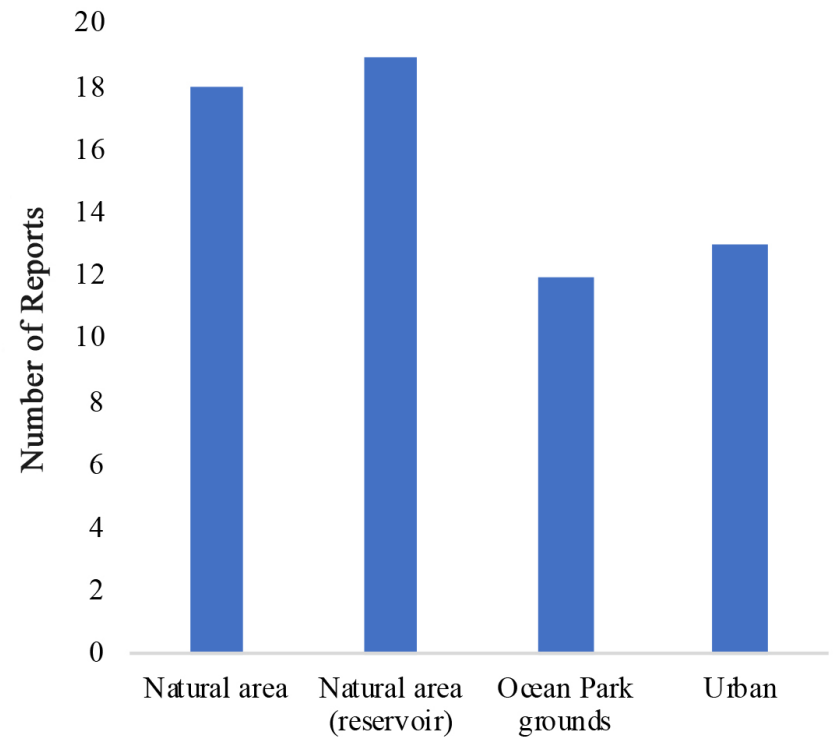

Fig. 3. Land use context of reports of the Chinese Water Dragon (Physignathus cocincinus) in Hong Kong.

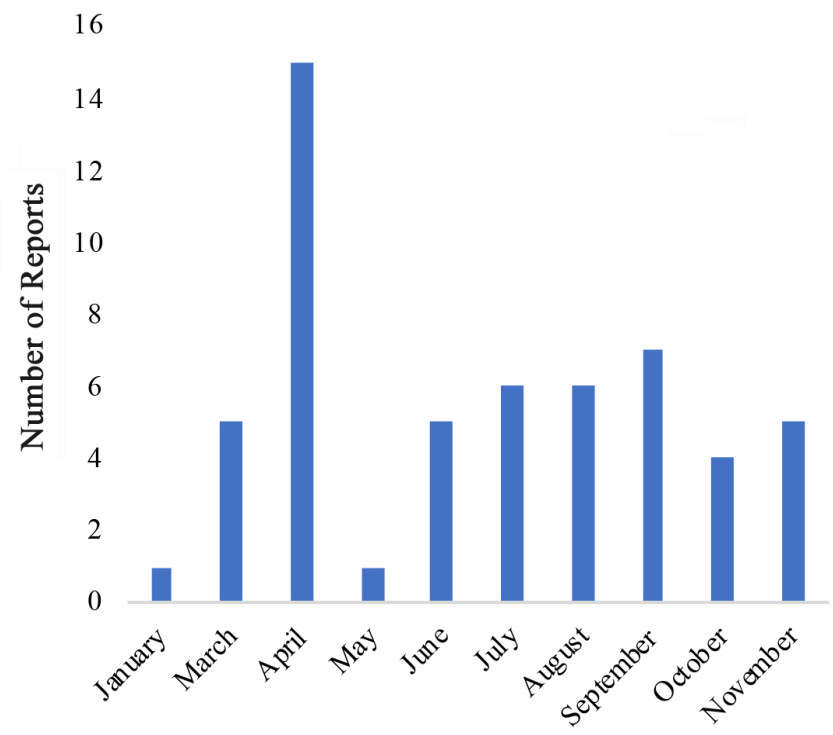

Fig. 4. Seasonality of reports of the Chinese Water Dragon (Physignathus cocincinus) in Hong Kong.
Table 2. Number of adult male, adult female, and juvenile Chinese Water Dragons (Physignathus cocincinus) reported in different locations in Hong Kong. Proportions of each demographic at each location are shown in parentheses (\%).

\section{Males Females Juveniles}

\begin{tabular}{lccc}
\hline Hong Kong Island & & & \\
\hline Aberdeen & $4(27)$ & $9(60)$ & $2(13)$ \\
\hline Chai Wan Gap & & & $1(100)$ \\
\hline Pok Fu Lam Reservoir & $8(57)$ & $5(36)$ & $1(7)$ \\
\hline Wan Chai & $1(100)$ & & \\
\hline
\end{tabular}

\begin{tabular}{lccc}
\hline New Territories & & \\
\hline Cha Liu Au & & $1(100)$ & \\
\hline Kam Shan Country Park & $3(100)$ & & \\
\hline Lantau Island & $1(100)$ & & \\
\hline Lion Rock Country Park & $3(43)$ & $1(14)$ & $3(43)$ \\
\hline Sha Tin District & $3(43)$ & $3(43)$ & $1(14)$ \\
\hline Tai Lam Country Park & $1(50)$ & $1(50)$ & \\
\hline Tsim Sha Tsui & $1(100)$ & & \\
\hline Tsing Yi Island & $3(38)$ & $2(25)$ & $3(38)$ \\
\hline Wong Tai Sin & $1(100)$ & & \\
\hline Total & $\mathbf{2 9 ( 4 7 )}$ & $\mathbf{2 2 ( 3 6 )}$ & $\mathbf{1 1 ( 1 8 )}$ \\
\hline
\end{tabular}

one fifth of reports. A similar proportion of reports were from the grounds of Ocean Park, which were treated separately here because the theme park has large tracts of natural areas interspersed with developed land that receives high visitation. The seasonality of reports was strongly biased towards the month of April, which accounted for one quarter of reports (Fig. 4). This was primarily driven by the surge in reports of dragons on the grounds of Ocean Park in April 2018. Higher numbers of reports also were documented from July to September.

The highest proportion of Chinese Water Dragons reported were adult males (Table 2). Juvenile dragons comprised slightly less than one fifth of reports and were distributed across six locations. Combinations of males and females were identified in Aberdeen, Pok Fu Lam Reservoir, Lion Rock Country Park, and Sha Tin, which suggests that populations in these locations could be self-sustaining. All three dragons recorded in and near the Kam Shan Country Park were adult males; however, the sample size is currently too small to rule out breeding potential.

This study proposes that the Chinese Water Dragon has established populations in at least four locations in Hong Kong. Although the initial incursion was observed on Tsing Yi Island (To 2005), the lack of further reports suggests that the incursion has not continued. The closest locations in subsequent reports were Lantau Island and the Kam Shan Country Park, both of which are separated by sea. 
Throughout the world, non-native species introduced into new ecosystems have a range of negative impacts (e.g., Matyot 2004). These include predation and/or competition pressures on populations of native species and the possible transmission of diseases (Mutze et al. 2014; Mo 2017; Radford et al. 2018). Historically, the Changeable Lizard (Calotes versicolor) was the sole agamid in Hong Kong (Karsen et al. 1998). The establishment of the Chinese Water Dragon in Hong Kong clearly illustrates the consequences of the exotic pet trade on local faunal assemblages (e,g., Reaser and Meyers 2007; Mo 2019). This species has also been introduced to Taiwan (Lee et al. 2019), Penang, Malaysia (Grismer and Quah 2019), and Florida, USA (Ferriter et al. 2009). Both in these locations and Hong Kong, the effects of Chinese Water Dragons on local ecosystems have yet to be quantified. Ciou (2015) reported predation on native lizards, frogs, snakes, and small mammals in Taiwan, which is suggestive of predation pressures imposed on native species.

\section{Acknowledgements}

The data in this study were generated from information posted by individuals using citizen-science, social media, and photography-sharing platforms. The preparation of this paper was assisted by useful discussions with Paul Crow and recent observations by David and Tammy Mo and Jaxon and Kayden Lee.

\section{Literature Cited}

Bogadek, A. and M.W.N. Lau. 1997. A revised checklist of Hong Kong amphibians and reptiles. Memoirs of the Hong Kong Natural History Society 21: 173-188.

Chan, S.K.F., K. Cheung, C. Ho, F. Lam, and W. Tang. 2006. The geckos of Hong Kong, pp. 1-9. In: Hong Kong Biodiversity. Agriculture, Fisheries and Conservation Department, Government of the Hong Kong Special Administrative Region, Kowloon, Hong Kong.

Ciou, B.K. 2015. Study on food habits of the invasive Asian Water Dragon Physignathus cocincinus in Taiwan. Unpublished Master's thesis, National Taipei University of Education, Taipei, Taiwan.

Corlett, R. 1992. Second population of Brooke's Gecko. Porcupine 2: 4.

Ferriter, A., B. Doren, R. Winston, D. Thayer, B. Miller, B. Thomas, M. Barrett, T. Pernas, S. Hardin, J. Lane, M. Kobza, D. Schmitz, M. Bodle, L. Toth, L.
Rodgers, P. Pratt, S. Snow, and C. Goodyear. 2009. The status of nonindigenous species in the South Florida environment, pp. 1-101. In: G. Redfield (ed.), South Florida Environmental Report. South Florida Water Management District, West Palm Beach, Florida, USA.

Grismer, L.L. and E.S.H. Quah. 2019. An updated and annotated checklist of the lizards of Peninsular Malaysia, Singapore, and their adjacent archipelagos. Zootaxa 4545: 230-248.

Karsen, S.J., M.W.N. Lau, and A. Bogadek. 1998. Hong Kong Amphibians and Reptiles. The Provisional Urban Council, Hong Kong.

Lau, M.W.N., G. Ades, N. Goodyer, and F.S. Zou. 1997. Wildlife trade in southern China including Hong Kong and Macau, pp. 141-159. In: J. MacKinnon (ed.), Conserving China's Biodiversity. China Environmental Science Press, Beijing, China.

Lau, M., B. Chan, P. Crow, and G. Ades. 2000. Trade and conservation of turtles and tortoises in the Hong Kong Special Administrative Region, People's Republic of China, pp. 39-44. In: P.P. van Dijk, B.L. Stuart, and A.G.J. Rhodin (eds.), Asian Turtle Trade: Proceedings of a Workshop on Conservation and Trade of Freshwater Turtles and Tortoises in Asia. Chelonian Research Foundation, Lunenburg, Massachusetts, USA.

Lee, K-H., T-H. Chen, G. Shang, S. Clulow, Y-J. Yang, and S-M. Lin. 2019. A check list and population trends of invasive amphibians and reptiles in Taiwan. Zookeys 829: 85-130.

Matyot, P. 2004. The establishment of the Crested Tree Lizard, Calotes versicolor (Daudin, 1802) (Squamata: Agamidae), in Seychelles. Phelsuma 12: 35-47.

Mo, M. 2017. Asian Black-spined Toads (Duttaphynus melanostictus) in Australia: An invasion worth avoiding. Reptiles \& Amphibians 24: 155-161.

Mo, M. 2019. Possible records of Yellow-bellied Sliders (Trachemys scripta scripta) or River Cooters (Pseudemys concinna) in Hong Kong. Reptiles \& Amphibians 26: $51-53$.

Mutze, G., B. Cooke, M. Lethbridge, and S. Jennings. 2014. A rapid survey method for estimating population density of European rabbits living in native vegetation. Rangeland Journal 36: 239-247.

Radford, J.Q., J.C.Z. Woinarski, S. Legge, M. Baseler, J. Bentley, A.A. Burbidge, M. Bode, P. Copley, N. Dexter, C.R. Dickman, G. Gillespie, B. Hill, C.N. Johnson, J. Kanowski, P. Latch, M. Letnic, A. Manning, P. Menkhorst, N. Mitchell, K. Morris, K. Moseby, M. Page, and J. Ringma. 2018. Degrees of population-level susceptibility of Australian terrestrial non-volant mammal species to predation by the introduced Red Fox (Vulpes vulpes) and feral cat (Felis catus). Wildlife Research 45: 645-657.

Reaser, J.K. and M. Meyers. 2007. HabitattitudeTM: Getting a backbone about the pet release pathway, pp. 63-71. In: G.W. Witmer, W.C. Pitt, and K.A. Fagerstone (eds.), Managing Vertebrate Invasive Species: Proceedings of an International Symposium. United States Department of Agriculture, Fort Collins, Colorado, USA.

Stringham, O.C. and J.L. Lockwood. 2018. Pet problems: Biological and economic factors that influence the release of alien reptiles and amphibians by pet owners. Journal of Applied Ecology 55: 2632-2640.

To, A. 2005. Another alien has landed: The discovery of a wild population of water dragon, Physignathus cocincinus, in Hong Kong. Porcupine 33: 3-4. 